ARTICLE

https://doi.org/10.1038/s41467-019-11836-z

\title{
Rate and selectivity hysteresis during the carbon monoxide hydrogenation over promoted $\mathrm{Co} / \mathrm{MnOx}$ catalysts
}

\author{
Yizhi Xiang (1) 1,4, Libor Kovarik ${ }^{2}$ \& Norbert Kruse (1) 1,3
}

While cobalt-based catalysts have been used in industrial Fischer-Tropsch synthesis for decades, little is known about how the dynamics of the $\mathrm{Co}_{-} \mathrm{CO}_{2} \mathrm{C}$ phase transformation drive their performance. Here we report on the occurrence of hysteresis effects in the FischerTropsch reaction over potassium promoted $\mathrm{Co} / \mathrm{MnO}_{x}$ catalyst. Both the reaction rate and the selectivity to chain-lengthened paraffins and terminally functionalized products (aldehydes, alcohols, olefins) show bistability when varying the hydrogen/carbon monoxide partial pressures back and forth from overall reducing to carbidizing conditions. While the carbon monoxide conversion and the selectivity to functionalized products follow clockwise hysteresis, the selectivity to paraffins shows counter-clockwise behavior. In situ X-ray diffraction demonstrates the activity/selectivity bistability to be driven by a $\mathrm{Co}-\mathrm{Co}_{2} \mathrm{C}$ phase transformation. The conclusions are supported by High Resolution Transmission Electron Microscopy which identifies the $\mathrm{Co}-\mathrm{Co}_{2} \mathrm{C}$ transformation, $\mathrm{Mn}_{5} \mathrm{O}_{8}$ layered topologies at low $\mathrm{H}_{2} / \mathrm{CO}$ partial pressure ratios, and $\mathrm{MnO}$ at high such ratios.

\footnotetext{
${ }^{1}$ Voiland School of Chemical Engineering and Bioengineering, Washington State University, Pullman, WA 99164, USA. ${ }^{2}$ Environmental Molecular Science Laboratory, Pacific Northwest National Laboratory, P.O. Box 999Richland, WA 99352, USA. ${ }^{3}$ Institute for Integrated Catalysis, Pacific Northwest National Laboratory, Richland, WA 99332, USA. ${ }^{4}$ Present address: Dave C. Swalm School of Chemical Engineering, Mississippi State University, Mississippi State, MS 39762, USA. Correspondence and requests for materials should be addressed to N.K. (email: norbert.kruse@wsu.edu)
} 
$\mathrm{C}$ atalytic reactions occur far from equilibrium. Consequently, multiple steady states may be observed along with kinetic hysteresis effects. Both clockwise and counterclockwise dynamic hysteresis may occur upon variation of critical reaction parameters. The reason for the occurrence of hysteretic response behavior can frequently be related to competitive and asymmetric reactant adsorption or, more generally, to inhibition effects following, for example, concentration-dependent catalyst phase transitions. While considerable foundational knowledge has been acquired over the past three decades on kinetic nonlinearities of seemingly simple catalytic surface reactions like the $\mathrm{CO}$ oxidation or $\mathrm{NO}_{\mathrm{x}}$ reduction ${ }^{1}$, much less information is presently available for complex reaction networks with varying product selectivity. An excellent example is the CO hydrogenation according to Fischer-Tropsch (F-T), which may lead to the production of chain-lengthened hydrocarbons and terminally functionalized oxygenates over Co-based and Fe-based catalysts $^{2,3}$.

Historically, one of the earliest observations of a $\mathrm{F}-\mathrm{T}$ reactioninduced chemical phase transition was made for Fe-based catalysts $^{4}$, which were found to transform into carbide structures through pre-carbidization of iron oxide with CO or syngas ${ }^{5}$ or, more recently, during the ongoing $\mathrm{F}-\mathrm{T}$ reaction using $\mathrm{Fe}(0)^{6-8}$ as activated precursor. By contrast, bulk cobalt carbides were commonly not observed, and therefore not considered as being relevant for the construction of the catalytically active phase ${ }^{9-16}$. Moreover, bulk cobalt carbides were actually considered thermodynamically metastable since they decomposed under inert atmosphere and in the presence of $\mathrm{H}_{2}$ at elevated temperatures ${ }^{17,18}$. Mohandas et al. ${ }^{15}$ and Claeys et al. ${ }^{19}$ observed that, under $\mathrm{F}-\mathrm{T}$ reaction conditions, as-prepared $\mathrm{Co}_{2} \mathrm{C}$ can be converted into metallic cobalt at temperatures above $220^{\circ} \mathrm{C}$. Nevertheless, the formation of $\mathrm{Co}_{2} \mathrm{C}$ was occasionally observed through exposure of reduced cobalt to pure $\mathrm{CO}$ and found to be strongly dependent on the choice of the support material and time-on-stream in syngas ${ }^{16,20}$. More recently, Paterson et al. reported a nice demonstration of Ostwald's Stufenregel ("rule of stages") when transforming $\mathrm{Co}_{3} \mathrm{O}_{4}$ spinel stepwise into hexagonal $\mathrm{Co}_{2} \mathrm{C}$ by exposure to $\mathrm{CO}^{21}$. Particular attention received on $\mathrm{Co}_{2} \mathrm{C}$ formation during $\mathrm{F}-\mathrm{T}$ synthesis over Co-based catalysts promoted by $\mathrm{Mn}$ and/or alkali ${ }^{22-27}$. Such catalysts demonstrated a remarkable capacity in producing terminally functionalized products, such as n-aldehydes ${ }^{22}$, n-alcohols ${ }^{25,28,29}$, or olefins ${ }^{23,24,26,27}$. The promoting effect of $\mathrm{Mn}$ on the formation of $\mathrm{Co}_{2} \mathrm{C}$ during the $\mathrm{F}-\mathrm{T}$ reaction was recently investigated by Ding et al. ${ }^{25}$. The authors suggested that $\mathrm{Mn}$ facilitates the dissociation and disproportionation of $\mathrm{CO}$ and suppresses $\mathrm{H}_{2}$ adsorption on the catalyst surface, thereby creating a relatively $\mathrm{C}$-rich and $\mathrm{H}$ lean surface chemical environment. Similar arguments were previously advanced by Johnson et al. ${ }^{30,31}$ to explain the high selectivity of $\mathrm{C}_{5+}$ products and olefins, at the expense of methane. Overall, however, little is known about how the kinetics of the $\mathrm{Co}-\mathrm{Co}_{2} \mathrm{C}$ phase transformation drive both reaction rate and selectivity.

Here, we show kinetic hysteresis in the F-T reaction and identify compositional changes of the catalyst to drive this hysteresis in the absence of thermokinetic effects. Using a potassiumpromoted $\mathrm{Co} / \mathrm{MnO}_{\mathrm{x}}$ catalyst with $\mathrm{Co}_{4} \mathrm{Mn}_{1} \mathrm{~K}_{0 \cdot 1}$ metal atomic composition, which was previously shown to produce more than $60 \mathrm{wt} \% \mathrm{n}$-aldehydes under $\mathrm{H}_{2}$-lean conditions of the $\mathrm{F}-\mathrm{T}$ reaction $^{22}$, we will demonstrate the occurrence of rate and selectivity hysteresis while cycling the syngas composition from high $\mathrm{P}_{\mathrm{H} 2} /$ $\mathrm{P}_{\mathrm{CO}}$ to low and back to high such ratio. Two steady states with distinct rate-selectivity signatures are produced this way for a unique point in the parameter space; only the direction of the $\mathrm{P}_{\mathrm{H} 2} / \mathrm{P}_{\mathrm{CO}}$ variation matters when approaching such points within the bistability regime. This history dependence of the system will be shown to be exclusively dependent on and driven by the kinetic $\mathrm{Co}-\mathrm{Co}_{2} \mathrm{C}$ phase transition.

\section{Results}

Catalytic results. We first turn to our catalytic results, which are shown in Fig. 1. Obviously, both the CO conversion and the selectivity depend on whether the $\mathrm{P}_{\mathrm{H} 2} / \mathrm{P}_{\mathrm{CO}}$ ratio is increased or decreased. Each data point in Fig. 1 represents quasi-steady-state behavior after $\sim 12 \mathrm{~h}$ time-on-stream. We also note that three samples of the same batch of $\mathrm{Co}_{4} \mathrm{Mn}_{1} \mathrm{~K}_{0 \cdot 1}$ catalyst are being investigated while varying the $\mathrm{P}_{\mathrm{H} 2} / \mathrm{P}_{\mathrm{CO}}$ ratio. The results of these measurements fit into the same Fig. 1 without difficulties. With regard to the catalytic activity, the $\mathrm{CO}$ conversion (panel a) obviously shows clockwise hysteresis, i.e., a low reactivity state (LRS) is followed when decreasing the $\mathrm{P}_{\mathrm{H} 2} / \mathrm{P}_{\mathrm{CO}}$ ratio from initially high $(30 / 1)$ to low and, vice versa, a high-reactivity state (HRS) is followed when increasing this ratio back to high again. In particular, while the CO conversion is up to $20 \%$, at the most (at $\mathrm{P}_{\mathrm{H} 2} / \mathrm{P}_{\mathrm{CO}}=30$ ), and less than $10 \%$ for $5 \leq \mathrm{P}_{\mathrm{H} 2} / \mathrm{P}_{\mathrm{CO}} \leq 10$, on the LRS branch, it increases significantly to $75 \%$ at $\mathrm{P}_{\mathrm{H} 2} / \mathrm{P}_{\mathrm{CO}}=9$ and up to $90 \%$ at $\mathrm{P}_{\mathrm{H} 2} / \mathrm{P}_{\mathrm{CO}}=30$ on the HRS branch. The bifurcation between LRS and HRS seems to occur at $\mathrm{P}_{\mathrm{H} 2} / \mathrm{P}_{\mathrm{CO}} \sim 3$. The hysteresis loop finally closes by running the catalyst under pure $\mathrm{H}_{2}$, i.e., removing $\mathrm{CO}$ from the reaction mixture at $220^{\circ} \mathrm{C}$ and $40 \mathrm{bar}$ (indicated by a green dashed line in Fig. 1). A similar hysteresis distinguishing the low reactivity from the high-reactivity branch is obtained when plotting the specific reaction rate rather than conversion (Supplementary Fig. 1). The slight misfit between "start" and "end" in both conversion and rate hysteresis (as well as the selectivity hysteresis discussed below) is probably associated with irreversible changes of the Co metallic phase which is mainly fcc besides less hcp when starting and rather equally distributed between hcp and fcc when finishing the experiments (see below for XRD and HRTEM results). We note that the transition from $\mathrm{H}_{2} / \mathrm{CO}=30$ to pure $\mathrm{H}_{2}$ (rather than systematically establishing higher such ratios) has technical reasons related to the back pressure control at very low $\mathrm{CO}$ gas pressures.

While CO conversion follows clockwise hysteresis, both clockwise and counter-clockwise hysteresis are observed for selectivity. Most notable hysteresis loops occur for paraffins and alcohols. Starting with essentially $100 \%$ selectivity (of which $70 \%$ are allotted to methane, see Supplementary Fig. 2a for methane selectivity hysteresis, at $\mathrm{P}_{\mathrm{H} 2} / \mathrm{P}_{\mathrm{CO}}=30 / 1$ ), the yield in paraffins drops significantly at $\mathrm{P}_{\mathrm{H} 2} / \mathrm{P}_{\mathrm{CO}} \leq 5 / 1$. Under partial pressure conditions typically applied in $\mathrm{F}-\mathrm{T}$ synthesis $\left(1 \leq \mathrm{P}_{\mathrm{H} 2} / \mathrm{P}_{\mathrm{CO}} \leq 3\right)$, paraffin selectivities are between 30 and $\sim 40 \%$. For understoichiometric reaction conditions, $\mathrm{P}_{\mathrm{H} 2} / \mathrm{P}_{\mathrm{CO}}=0.5$, only $20 \%$ of paraffins are detected. When increasing the $\mathrm{P}_{\mathrm{H} 2} / \mathrm{P}_{\mathrm{CO}}$ ratios from low to high, paraffin selectivities set out on their way back, but remain considerably lower than those of the forward run. A (nearly) closed hysteresis loop is obtained when subjecting the catalyst to pure $\mathrm{H}_{2}$ conditions. Thus, compared with the clockwise hysteresis of the CO conversion, an overall counterclockwise behavior is seen for the paraffin selectivity. Interestingly, terminal alcohols and total oxygenates (see Supplementary Fig. 2b for total oxygenates selectivity hysteresis) run counter paraffins, i.e., show clockwise hysteresis: while alcohol selectivities are low for initially high $\mathrm{P}_{\mathrm{H} 2} / \mathrm{P}_{\mathrm{CO}}$ ratios, they are significantly higher when increasing these ratios from low to high. A maximum alcohol production of $\sim 45 \%$ is found for $\mathrm{P}_{\mathrm{H} 2} / \mathrm{P}_{\mathrm{CO}}=$ 5. Larger such ratios cause a gradual decline of alcohols.

Turning to aldehydes and olefins, we note that both products can be easily hydrogenated into alcohols and paraffins, respectively, under hydrogen-rich conditions. Therefore, the hysteresis 

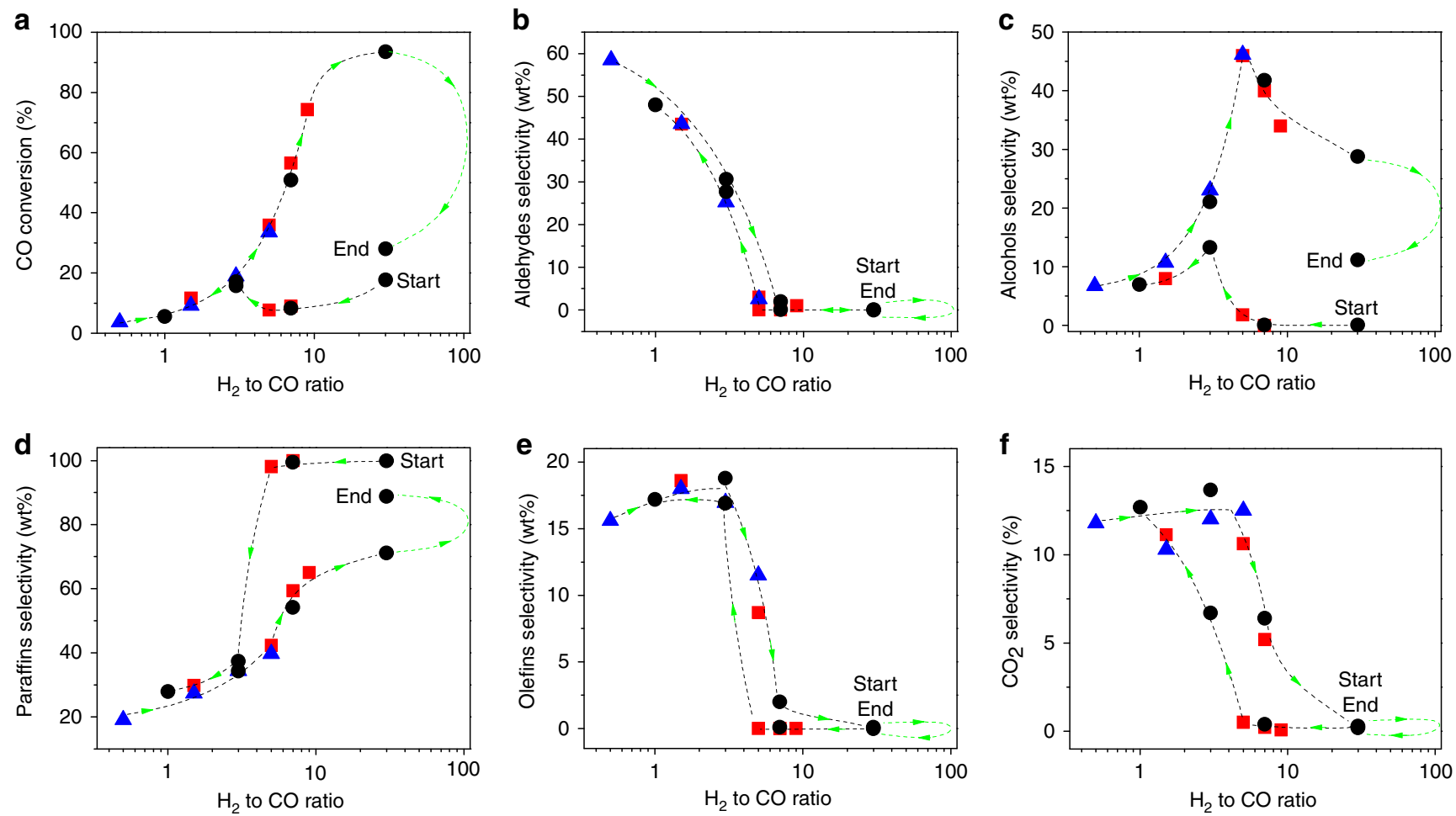

Fig. 1 Kinetic hysteresis in the catalytic CO hydrogenation. a CO conversion; b-e selectivities of aldehydes, alcohols, paraffins and olefins, respectively (ex $\mathrm{CO}_{2}$ ); $\mathbf{f} \mathrm{CO}_{2}$ selectivity. The same batch of catalyst is tested independently three times (circle), (square), and (triangle) over $0.5 \mathrm{~g} \mathrm{Co}{ }_{4} \mathrm{Mn}_{1} \mathrm{~K}_{0 \cdot 1}$ at $220{ }^{\circ} \mathrm{C}_{1}$ 40 bar, and GHSV $=3600 \mathrm{~h}^{-1}$. During each run, the $\mathrm{P}_{\mathrm{H} 2} / \mathrm{P}_{\text {CO }}$ ratio is varied systematically as follows: (circle) $30 / 1 \rightarrow 7 / 1 \rightarrow 3 / 1 \rightarrow 1 / 1 \rightarrow 7 / 1 \rightarrow 30 / 1 \rightarrow$ 30/1 (after $\mathrm{H}_{2}$ treatment for $8 \mathrm{~h}$ : green dashed line), (square) $7 / 1 \rightarrow 5 / 1 \rightarrow 1.5 / 1 \rightarrow 5 / 1 \rightarrow 7 / 1 \rightarrow 9 / 1$, (triangle) $0.5 / 1 \rightarrow 1.5 / 1 \rightarrow 3 / 1 \rightarrow 5 / 1$. Each data point reflects quasi-steady-state conditions after $12 \mathrm{~h}$ time-on-stream

loops for aldehydes and olefins are much less distinct and absent for $\mathrm{P}_{\mathrm{H} 2} / \mathrm{P}_{\mathrm{CO}} \geq 5$. Remarkably, while neither aldehydes nor olefins are ever produced for $\mathrm{P}_{\mathrm{H} 2} / \mathrm{P}_{\mathrm{CO}}>5$, overall $60 \%$ of aldehydes and $15 \%$ of olefins $\left(\mathrm{ex} \mathrm{CO}_{2}\right)$ are obtained at $\mathrm{P}_{\mathrm{H} 2} / \mathrm{P}_{\mathrm{CO}}=0.5$. Under these conditions, methane formation is low $(\sim 5 \%)$, see Supplementary Fig. 2a. More detailed product distributions along the LRS and HRS branches under the same reaction conditions can be found in Supplementary Fig. 3.

Finally, $\mathrm{CO}_{2}$ formation also shows significant clockwise hysteresis. For very high partial pressure ratios, $\mathrm{P}_{\mathrm{H} 2} / \mathrm{P}_{\mathrm{CO}}>9$, no $\mathrm{CO}_{2}$ at all is formed. The highest $\mathrm{CO}_{2}$ selectivites occur at low such ratios, but remain below $\sim 13 \%$ all the time. The observed hysteresis suggests $\mathrm{CO}_{2}$ formation to involve similar surface precursors as hydrocarbons and oxygenates rather than originating from the water-gas shift reaction, $\mathrm{CO}+\mathrm{H}_{2} \mathrm{O} \leftrightarrow \mathrm{CO}_{2}+\mathrm{H}_{2}$.

Hysteresis effects as reported in this study raise the question for the intrinsic kinetics by which the steady states of the reaction are approached. We therefore measured the time dependence of changes in activity and product selectivity after switching the partial pressure ratios. One such measurement, carried out for a switch in $\mathrm{P}_{\mathrm{H} 2} / \mathrm{P}_{\mathrm{CO}}$ from $5 / 1$ to $1.5 / 1$, is provided in Supplementary Fig. 4. The data clearly show a nonlinear response behavior consisting in moderate changes of the product selectivity during the first $5 \mathrm{~h}$ time-on-stream (TOS) followed by a rapid drop of paraffins and raise of olefins (from $<5$ to $40 \%$ ) and oxygenates (from $<5$ to $20 \%$ ) within a short period of time. For $6 \leq$ TOS $\leq 12$, oxygenates further increase to reach a selectivity of $\sim 50 \%$ at the expense of both olefins and paraffins; close-to-steady state behavior for all product classes is obtained after $\sim 12 \mathrm{~h}$.

Product distributions in Fig. 1 have also been evaluated in terms of chain lengthening probabilities. Anderson-Schulz-Flory (ASF) plots have been constructed and are compiled in Fig. 2.

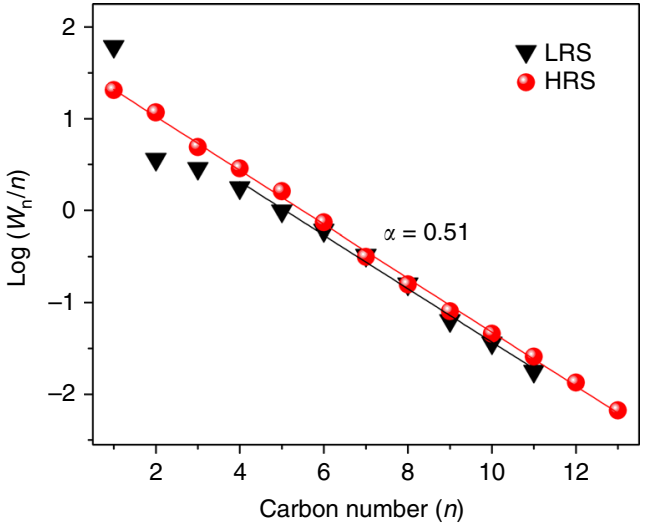

Fig. 2 ASF distribution for low and high-reactivity hysteresis branches. Obtained at a $\mathrm{H}_{2} / \mathrm{CO}$ partial pressure ratio of $5 / 1$ and otherwise identical reaction conditions as in Fig. 1. $W_{n}$ stands for the mass fraction of all products containing $n$ carbon atoms: $W_{n}=W_{n \text {, paraffins }}+W_{n \text {, olefins }}+W_{n}$, alcohols $+W_{n \text {, aldehydes }}$

Accordingly, a linear ASF behavior with unique chain lengthening probability $a=0.5$ is obtained for $\mathrm{C}_{4+}$ product distributions on both the LRS and HRS branch. However, significant deviations from the linear ASF behavior are seen for $C_{1}-C_{3}$ on the low rate branch. These deviations seem to be general; they also occur at pressure ratios other than $\mathrm{P}_{\mathrm{H} 2} / \mathrm{P}_{\mathrm{CO}}=5$ and are probably associated with variations in the composition of the "most abundant surface (reaction) intermediate ("masi" or "mari”).

Structural characterization. To demonstrate that changes in the structure and composition of the catalyst correlate with the 


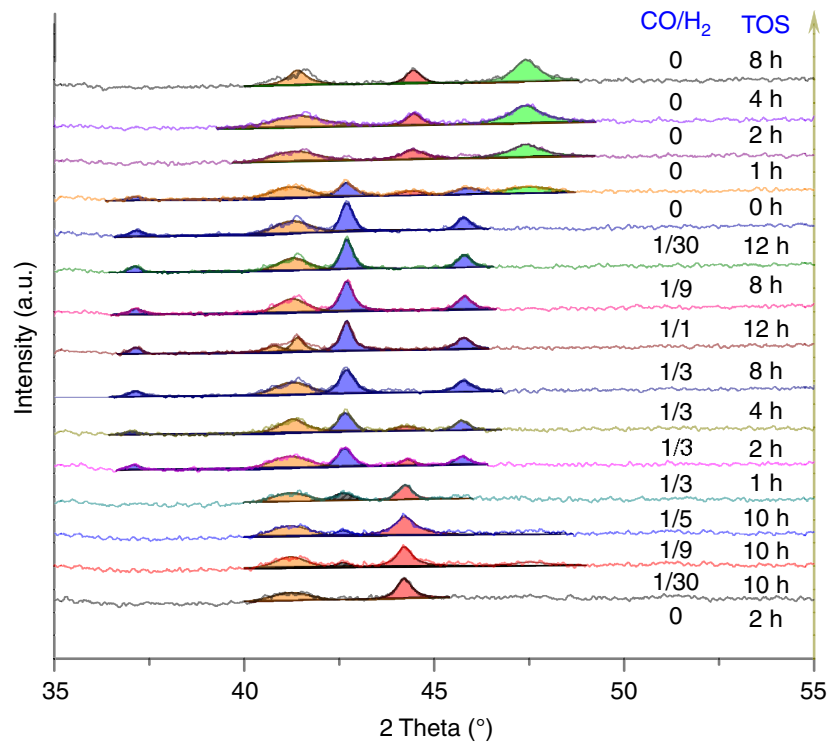

Fig. 3 In situ $X R D$ of a $\mathrm{Co}_{4} \mathrm{Mn}_{1} \mathrm{~K}_{0 \cdot 1}$ catalyst. The results refer to a reaction temperature of $220^{\circ} \mathrm{C}$ and atmospheric pressure. The same batch of catalyst was sequentially (from low to up) exposed to pure $\mathrm{H}_{2}$ or syngas (at various $\mathrm{p}_{\mathrm{CO}} / \mathrm{p}_{\mathrm{H} 2}$ ) for different times-on-stream (TOS), see also Fig. S5. Red peaks indicate fcc cobalt (111), blue and green peaks are due to $\mathrm{Co}_{2} \mathrm{C}$ and hcp cobalt, respectively. Orange peaks at $2 \theta \sim 41.3^{\circ}$ are either $\mathrm{Co}_{2} \mathrm{C}(020)$ or hcp Co

occurrence of kinetic hysteresis effects as described above, we have performed X-ray diffraction (XRD) experiments. To ensure this correlation also applies under in-operando (atmospheric) conditions, some of the XRD experiments have been made while following the catalytic production on-line. The general trend of hysteretic reaction behaviors has been reproduced this way. In Fig. 3, we focus on in situ XRD experiments to systematically follow the bulk Co composition for varying $\mathrm{P}_{\mathrm{H} 2} / \mathrm{P}_{\mathrm{CO}}$ ratios. As seen in this Fig. (and also in Supplementary Fig. 5), only pure metallic cobalt phases (mainly represented by the (111) plane of Co fcc at $2 \theta \sim 44.3^{\circ}$, JCPDS 15-0806) are observed for virgin $\mathrm{Co}_{4} \mathrm{Mn}_{1} \mathrm{~K}_{0 \cdot 1}$ after treatment in pure $\mathrm{H}_{2}$. Almost identical diffraction patterns occur after exposing the catalyst to $\mathrm{H}_{2}$-rich syngas $\left(\mathrm{P}_{\mathrm{H} 2} / \mathrm{P}_{\mathrm{CO}}=30 / 1\right)$ for $10 \mathrm{~h}$. While metal diffraction remains the main phase when increasing the $\mathrm{CO}$ partial pressure to adjust $\mathrm{P}_{\mathrm{H} 2} / \mathrm{P}_{\mathrm{CO}}=9 / 1$ and $5 / 1$, trace amounts of $\mathrm{Co}_{2} \mathrm{C}$ diffraction are observed at $2 \theta \sim 42.5^{\circ}$ (JCPDS 05-0704). Interestingly, metallic cobalt diffraction fades away when further increasing the $\mathrm{CO}$ partial pressure to reach $\mathrm{P}_{\mathrm{H} 2} / \mathrm{P}_{\mathrm{CO}}=3 / 1$; after $8 \mathrm{~h}$ time-onstream at this pressure ratio hardly any metallic Co diffraction persists (for a detailed evolution of cobalt and $\mathrm{Co}_{2} \mathrm{C}$ diffraction lines as a function of time-on-stream see Supplementary Fig. 5). The diffraction lines (blue) centered at $2 \theta$ of 37.1, 41.4, 42.5, and $45.8^{\circ}$ correspond to the (011), (020), (111), and (210) planes of $\mathrm{Co}_{2} \mathrm{C}$ (JCPDS 05-0704). For a partial pressure ratio $\mathrm{P}_{\mathrm{H} 2} / \mathrm{P}_{\mathrm{CO}}=1$ / $1, \mathrm{Co}_{2} \mathrm{C}$ is definitely the only diffraction phase left. Strikingly, when decreasing the $\mathrm{CO}$ partial pressure from high back to low again $\left(\mathrm{P}_{\mathrm{H} 2} / \mathrm{P}_{\mathrm{CO}}=9 / 1\right.$ and $\left.30 / 1\right)$ no change in the diffraction pattern is encountered. We therefore conclude that the back transformation of the $\mathrm{Co}_{2} \mathrm{C}$ phase to metallic Co is slow under $\mathrm{H}_{2}$-rich syngas conditions. However, after exposing the catalyst to pure $\mathrm{H}_{2}$ at $220^{\circ} \mathrm{C}$ for $2 \mathrm{~h}$, both fcc and hcp cobalt phases are retrieved. This behavior is reminiscent of reports on the $\mathrm{Co}_{2} \mathrm{C}$ metastability in the presence of $\mathrm{H}_{2}{ }^{18}$ and the decomposition of $\mathrm{Co}_{2} \mathrm{C}$ to hcp cobalt and graphite ${ }^{32}$. On the other hand, cobalt carbide formation under $\mathrm{H}_{2}$-rich $\left(\mathrm{H}_{2} / \mathrm{CO}=9\right) \mathrm{F}-\mathrm{T}$ synthesis conditions was reported by Ducreux et al. ${ }^{33}$. Different from these earlier reports, our measurements clearly establish a hysteresis effect in the $\mathrm{Co}-\mathrm{Co}_{2} \mathrm{C}$ reversible transition. Closed hysteresis loops involving the complete back transformation of $\mathrm{Co}_{2} \mathrm{C}$ into metallic Co are obtained after treatment in pure $\mathrm{H}_{2}$ (or at very high $\mathrm{P}_{\mathrm{H} 2} / \mathrm{P}_{\mathrm{CO}}$ ratios $>30$ ).

The correlation of a reversible chemical reconstruction of $\mathrm{Co}$ particles and the catalytic performance in terms of activity and selectivity ultimately lead to a remarkable hysteresis behavior, in which Co metallic phases correlate with high paraffin and $\mathrm{Co}_{2} \mathrm{C}$ with high oxygenate/olefin selectivity. However, questions as to the influence of the $\mathrm{MnO}_{\mathrm{x}}$ phase as a dispersant and/or promoter persist and will be tackled by high-resolution transmission electron microscopy (HRTEM), along with energy-dispersive Xray spectroscopy (EDS). To allow an as close as possible correlation of the catalytic test procedures preceding HRTEM/ EDS measurements with those leading to kinetic hysteresis effects as shown in Fig. 1, we have investigated the same batch of $\mathrm{Co}_{4} \mathrm{Mn}_{1} \mathrm{~K}_{0 \cdot 1}$ catalyst after reaction with $\mathrm{P}_{\mathrm{H} 2} / \mathrm{P}_{\mathrm{CO}}$ of 30 (Fig. $4 \mathrm{a}-\mathrm{c}$ ) and 1.5 (panels (d-f) of the same Fig.) for $12 \mathrm{~h}$ using a fresh charge of catalyst in both cases. To mimic possible "memory" effects in the chemical composition of the catalyst while changing the $\mathrm{P}_{\mathrm{H} 2} / \mathrm{P}_{\mathrm{CO}}$ ratio from low to high, we have subjected another sample charge to low such ratios $\left(\mathrm{P}_{\mathrm{H} 2} / \mathrm{P}_{\mathrm{CO}}=1.5\right)$ before adjusting the end-of-the-loop value $\mathrm{P}_{\mathrm{H} 2} / \mathrm{P}_{\mathrm{CO}}=30$. As can be seen in Fig. 4, both metallic and oxidic phases undergo significant structural and chemical alterations while varying the $\mathrm{P}_{\mathrm{H} 2} / \mathrm{P}_{\mathrm{CO}}$ ratio. The upper panel demonstrates Co metal particles to be mainly present in fcc and (to somewhat lesser extent) hcp phases under hydrogen-rich reaction conditions. It is interesting to note that bulk XRD has allowed identifying fcc Co rather than hcp, see Fig. 2. Running the catalytic reaction under CO-rich conditions, $\mathrm{P}_{\mathrm{H} 2} / \mathrm{P}_{\mathrm{CO}}=1.5$ (Fig. $4 \mathrm{~d}-\mathrm{f}$ ), causes metallic Co to entirely transform into $\mathrm{Co}_{2} \mathrm{C}$ and $\mathrm{MnO}_{\mathrm{x}}$ to develop lath-like $\mathrm{Mn}_{5} \mathrm{O}_{8}\left(\mathrm{Mn}(\mathrm{II})_{2} \mathrm{Mn}(\mathrm{IV})_{3} \mathrm{O}_{8}\right)$. The occurrence of the latter is in agreement with our previous studies under similar reaction conditions ${ }^{22}$. Most surprisingly, when moving from low $\mathrm{P}_{\mathrm{H} 2} / \mathrm{P}_{\mathrm{CO}}$ ratios back to higher ones (Fig. $4 \mathrm{~g}-\mathrm{i}$ ), major amounts of $\mathrm{Co}_{2} \mathrm{C}$ persist these strongly reducing conditions while $\mathrm{Mn}_{5} \mathrm{O}_{8}$ decomposes to develop smaller $\mathrm{MnO}$ aggregates with cubic rock-salt structure. Metallic Co phases reappear very slowly in mainly hcp and lesser fcc crystal structure at $\mathrm{P}_{\mathrm{H} 2} / \mathrm{P}_{\mathrm{CO}}=30$.

\section{Discussion}

We have shown in this communication that prominent structural changes of a potassium-promoted $\mathrm{Co} / \mathrm{MnO}_{\mathrm{x}}$ catalyst occur during the Fischer-Tropsch reaction. The systematic variation of the $\mathrm{H}_{2}$ /CO partial pressure ratios has allowed us to follow the reversible $\mathrm{Co}-\mathrm{Co}_{2} \mathrm{C}$ bulk phase transformation as a function of time using in situ XRD, complemented by representative ex situ HRTEM studies. Once being formed at low such ratios, $\mathrm{Co}_{2} \mathrm{C}$ has proven to be rather perseverant with regard to its reduction to metallic Co. This observation, which is not in accordance with earlier reports claiming the $\mathrm{Co}_{2} \mathrm{C}$ phase to be "metastable"17,18, seems to be a key factor responsible for the activity-selectivity hysteresis of the $\mathrm{CO}$ hydrogenation. Ignoring in a first approximation the influence of the $\mathrm{MnO}_{\mathrm{x}}$ phase and that of the potassium promoter, it seems that the occurrence of $\mathrm{Co}_{2} \mathrm{C}$ provides a positive feedback on chain-lengthened oxygenates and olefins formation. It is remarkable that at stoichiometric $\left(\mathrm{P}_{\mathrm{H} 2} / \mathrm{P}_{\mathrm{CO}}=2 / 1\right)$ as well as under-stoichiometric reaction conditions the combined selectivities of functionalized hydrocarbons range between $\sim 70$ and $\sim 83 \%$, at rather low $\mathrm{CO}$ conversion, while under $\mathrm{H}_{2}$-rich conditions, after entering the high-reactivity hysteresis branch, the product spectrum simplifies to $~ 35 \%$ 1-alcohols and $65 \%$ 

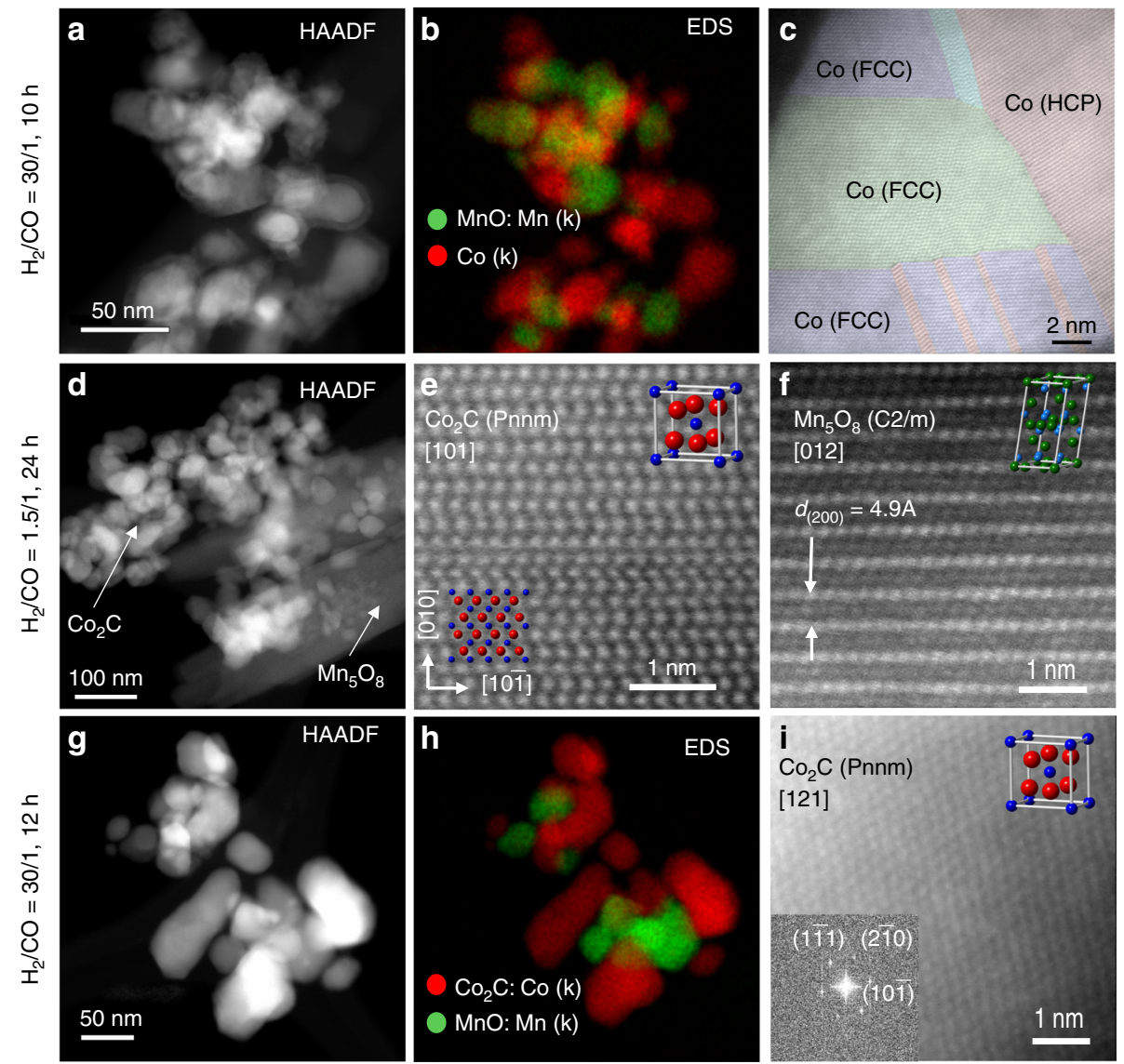

Fig. 4 HRTEM images along with EDS chemical mapping. The TEM image of the $\mathrm{Co}_{4} \mathrm{Mn}_{1} \mathrm{~K}_{0 \cdot 1}$ catalyst was obtained after $\mathrm{CO}$ hydrogenation at $22 \mathrm{O}^{\circ} \mathrm{C}$, $\mathrm{P}_{\text {total }}$ $=40$ bar. The partial pressure ratio is cycled between a-c: $\mathrm{H}_{2} / \mathrm{CO}=30, \mathbf{d}-\mathbf{f}: \mathrm{H}_{2} / \mathrm{CO}=1.5$, and g-i: back to $\mathrm{H}_{2} / \mathrm{CO}=30$. Sample history and time-onstream (TOS): a-c fresh catalyst after $12 \mathrm{~h}$ TOS, d-f: fresh catalyst after $24 \mathrm{~h}$ TOS, $\mathbf{g}$-i: catalyst subjected to $\mathrm{H}_{2} / \mathrm{CO}=1.5$ for $12 \mathrm{~h}$ first (as in $\mathbf{d}-\mathbf{f}$ ), then to successively increasing $\mathrm{H}_{2} / \mathrm{CO}$ ratios up to 30 (for another $12 \mathrm{~h}$ TOS). Scale bar for HAADF $50 \mathrm{~nm}$, scale bar for HRTEM $1 \mathrm{~nm}$

straight paraffins at a $\mathrm{CO}$ conversion of nearly $75 \%\left(\mathrm{P}_{\mathrm{H} 2} / \mathrm{P}_{\mathrm{CO}}=\right.$ 9/1).

In a previous study with $\mathrm{Mn}(\mathrm{II})$-promoted $\mathrm{Co} / \mathrm{SiO}_{2}$, Johnson et al. ${ }^{30,31}$ considered the high selectivity of $\mathrm{C}_{5+}$ formation with their catalyst as being due to an increase of $\mathrm{CO}_{\mathrm{ad}}$ concentrations, i.e., a decrease of the $\mathrm{H}_{\mathrm{ad}} / \mathrm{CO}_{\mathrm{ad}}$ ratios, following the strong Lewis acid-base interaction between $\mathrm{Mn}(\mathrm{II})$ and $\mathrm{CO}_{\mathrm{ad}}$. While the present paper provides clear evidence for the partial pressure ratio $\mathrm{P}_{\mathrm{H} 2} / \mathrm{P}_{\mathrm{CO}}$ to have a profound influence on the selectivity of the reaction, the amounts of $\mathrm{Mn}(\mathrm{II})$ (in $\mathrm{MnO}$ ) or $\mathrm{Mn}(\mathrm{II})-\mathrm{Mn}$ (IV) (in $\mathrm{Mn}_{5} \mathrm{O}_{8}$ ) employed in our study are far beyond the low $\mathrm{Mn}$ (II) promoter concentrations in $\mathrm{Co} / \mathrm{SiO}_{2}$. To the best of our knowledge, neither $\mathrm{Co} / \mathrm{SiO}_{2}$ nor $\mathrm{Co} / \mathrm{Al}_{2} \mathrm{O}_{3}$ catalysts have ever been reported to produce significant amounts of chain-lengthened oxygenates during $\mathrm{CO}$ hydrogenation. Such catalysts have also not been observed to undergo reaction-induced structural changes involving a $\mathrm{Co}-\mathrm{Co}_{2} \mathrm{C}$ bulk phase transition. We therefore conclude, in agreement with others ${ }^{23-27}$, that this phase transition is $\mathrm{MnO}_{\mathrm{x}}$ mediated. Different from $\mathrm{Si}(\mathrm{IV})$ or $\mathrm{Al}(\mathrm{III})$, the valence fluctionality between $\mathrm{Mn}$ (II) and $\mathrm{Mn}$ (IV) seems to play an important role in the bulk transformation of $\mathrm{Co}$ into $\mathrm{Co}_{2} \mathrm{C}$ and is therefore key to understanding the rich variety of functionalized products in the $\mathrm{CO}$ hydrogenation over CoMn-based catalysts.

The significant activity-selectivity hysteresis reported in this communication may raise the question for the possible occurrence of oscillatory behavior. So far, we have not yet observed any. If such periodic change in activity and selectivity occurs for the present system, under isothermal conditions and in the absence of mass transport limitations, we would anticipate a rather long-period behavior due to the slowness of the $\mathrm{Co}-\mathrm{Co}_{2} \mathrm{C}$ phase transition (speculating that this process would provide a suitable feedback for autonomous oscillations). Long-period oscillations are not unusual ${ }^{34}$ and were, for example, detected for the $\mathrm{NO} /$ /hydrogen reaction over Rh single-crystal surfaces ${ }^{35}$. In this case, the reversible oxidation of the $\mathrm{Rh}$ surface region was identified to provide the necessary feedback. A recent paper by Suchorski et al. ${ }^{36}$ reported intriguing results on the occurrence of multifrequential oscillations in the $\mathrm{O}_{2}-\mathrm{H}_{2}$ reaction over $\mathrm{Rh}$ and demonstrated the importance of reversible subsurface oxygen diffusion.

We finally note that nonisothermal self-sustained rate oscillations in the $\mathrm{F}-\mathrm{T}$ reaction were previously reported by Tsotsis et al. ${ }^{37}$. Both the reactor design as well as the catalyst system (Fe/ ZSM-5) were very different from ours, though. Due to the exothermicity of the reaction, the authors observed peak-to-peak amplitudes of about $150{ }^{\circ} \mathrm{C}$ in the reactor temperature. Such large jumps in temperature are clearly absent under our experimental conditions. The discovery of rate-selectivity hysteresis, as reported in this paper, opens new avenues to tune the catalytic performance of the Co-based Fischer-Tropsch reaction. We anticipate bistability not to be limited to potassium-promoted $\mathrm{Co} /$ $\mathrm{MnO}_{\mathrm{x}}$ catalysts but to apply to other systems with different selectivity signatures as well. 


\section{Methods}

Catalyst preparation. $\mathrm{Co}_{4} \mathrm{Mn}_{1} \mathrm{~K}_{0.1}$ catalyst was prepared via oxalate coprecipitation followed by thermal activation. To prepare the Co-Mn--K mixed oxalate precursor, first a solution of both $\mathrm{Co}\left(\mathrm{NO}_{3}\right)_{2} \cdot 6 \mathrm{H}_{2} \mathrm{O}$ and $\mathrm{Mn}\left(\mathrm{NO}_{3}\right)_{2} \cdot 4 \mathrm{H}_{2} \mathrm{O}$ in acetone $(100 \mathrm{ml})$, an aqueous solution of $\mathrm{KNO}_{3}(5 \mathrm{ml})$, and an acetone solution of $\mathrm{H}_{2} \mathrm{C}_{2} \mathrm{O}_{4} .2 \mathrm{H}_{2} \mathrm{O}(150 \mathrm{ml})$ were prepared in three separated beakers. Then the mixed acetone solution of $\mathrm{Co}\left(\mathrm{NO}_{3}\right)_{2} \cdot 6 \mathrm{H}_{2} \mathrm{O}$ and $\mathrm{Mn}\left(\mathrm{NO}_{3}\right)_{2} \cdot 4 \mathrm{H}_{2} \mathrm{O}$ together with the aqueous solution of $\mathrm{KNO}_{3}$ were added fast and simultaneously, under vigorous stirring, to the solution of $\mathrm{H}_{2} \mathrm{C}_{2} \mathrm{O}_{4} \cdot 2 \mathrm{H}_{2} \mathrm{O}$. Stirring was kept for at least 5 min until the color of the precipitates appeared homogeneous. Then the slurries were kept overnight for aging. After removal of the supernatant acetone, the precipitate was centrifuged and dried overnight at $110^{\circ} \mathrm{C}$. The obtained oxalate precursor was then treated thermally in the presence of hydrogen through stripping of $\mathrm{CO}_{2}$ under $\mathrm{H}_{2}$ $\left(30 \mathrm{ml} \mathrm{min}^{-1}\right)$ at $370^{\circ} \mathrm{C}$ for $1 \mathrm{~h}$. After activation, the BET surface area of the catalyst was $\sim 50 \mathrm{~m}^{2} / \mathrm{g}$

Catalyst characterization. X-ray diffraction (XRD) patterns of the catalysts were collected with a $\mathrm{Cu} \mathrm{Ka}$ source using a Rigaku Miniflex-600 X-ray diffractometer operating at $40 \mathrm{~mA}$ and $35 \mathrm{kV}$ in the continuous-scan mode with steps of 1 degree/ min in a wide $2 \theta$ angle range from 20 to $80^{\circ}$. High resolution Transmission electron microscopy (TEM) studies were performed with aberration corrected FEI Titan 80 300 operated at $300 \mathrm{kV}$. The instrument is equipped with a CEOS GmbH doublehexapole aberration corrector for the probe forming lens, which allows angstrom level resolution in scanning imaging modes. The present observations were performed in scanning mode using an HAADF detector. The probe convergence angle was $18 \mathrm{mrad}$, with an inner collection angle of $52 \mathrm{mrad}$. The EDS maps were collected with an aberration corrected Scanning Transmission Electron Microscope (STEM) (JEOL-ARM200F) operated at $200 \mathrm{kV}$. The instrument is equipped with a $100 \mathrm{~mm}^{2}$ Silicon Drift Detector ( 0.7srad, JEOL Centurio), allowing for high efficiency Energy Dispersive X-ray Spectroscopy. Acquisition and evaluation of the spectra was performed by NSS Thermo Scientific software package. In general, the STEM sample preparation involved mounting powder samples on copper grids covered with lacey carbon support films, and then immediately loading them into the TEM airlock.

Catalytic testing. High-pressure catalytic tests were performed in a fixed-bed plug-flow reactor $\left(\Phi_{\text {inner }}=7 \mathrm{~mm}\right)$. Typically, $1.3 \mathrm{~g}$ of oxalate were diluted with up to $2 \mathrm{~g}$ of $\mathrm{SiC}$ to achieve isothermal plug-flow conditions followed by in situ TPDec in $\mathrm{H}_{2}$ at $0.1 \mathrm{MPa}\left(30 \mathrm{ml} \mathrm{min}{ }^{-1}\right)$ and $370{ }^{\circ} \mathrm{C}$ for $1 \mathrm{~h}$ (after oxalate decomposition, the amount of activated catalyst is around $0.5 \mathrm{~g}$ ). The reactor was subsequently cooled to temperatures below $100^{\circ} \mathrm{C}$ in flowing hydrogen before adding $\mathrm{CO}$ to produce a syngas feed with a specific $\mathrm{H}_{2} / \mathrm{CO}$ pressure ratio. Metal carbonyls (mainly $\mathrm{Ni}(\mathrm{CO})_{4}$ ) were removed by passing the $\mathrm{CO}$ feed through a zeolite $4 \mathrm{~A}$ trap at high temperature before introduction into the reactor. The total flow rates $\left(\mathrm{H}_{2}+\right.$ CO) were fixed at $40 \mathrm{ml} \mathrm{min}{ }^{-1}$ providing GHSV $=3600 \mathrm{~h}^{-1}$ (Gas Hourly Space Velocity). After pressurizing the system to $40 \mathrm{bar}$, the temperature for the catalytic tests was raised using low heating rates of $1^{\circ} \mathrm{C} \mathrm{min}-1$ to $220^{\circ} \mathrm{C}$. Catalytic activities and product selectivities were determined after stabilization for at least $12 \mathrm{~h}$, and measured by an online GC-MS (Agilent 7890A GC/5975 MS).

\section{Data availability}

Any data that support the plots and calculations within this paper as well as other findings of this study can be available from the corresponding author upon reasonable request.

Received: 18 June 2019 Accepted: 6 August 2019

Published online: 02 September 2019

\section{References}

1. Imbihl, R. \& Ertl, G. Oscillatory kinetics in heterogeneous catalysis. Chem. Rev. 95, 697-733 (1995).

2. Fischer, F. \& Tropsch, H. Über die Herstellung synthetischer Ölgemische (Synthol) durch Aufbau aus Kohlenoxyd und Wasserstoff. Brennst. Chem. 4, 276-285 (1923).

3. Fischer, F. \& Tropsch, H. Die Erdölsynthese bei gewöhnlichem Druck aus den Vergasungsprodukten der Kohle. Brennst. Chem. 7, 97-104 (1926).

4. Bahr, H. A. \& Jessen, V. Die Kohlenoxyd-Spaltung am Kobalt. Ber. Dtsch Chem. Ges. 63, 2226-2237 (1930).

5. Bukur, D. B. et al. Activation studies with a promoted precipitated iron Fischer-Tropsch catalyst. Ind. Eng. Chem. Res. 28, 1130-1140 (1989).

6. Amelse, J. A., Butt, J. B. \& Schwartz, L. H. Carburization of supported iron synthesis catalysts. J. Phys. Chem. 82, 558-563 (1978).

7. Niemantsverdriet, J. W., Van der Kraan, A. M., Van Dijk, W. L. \& Van der Baan, H. S. Behavior of metallic iron catalysts during Fischer-Tropsch synthesis studied with Moessbauer spectroscopy, x-ray diffraction, carbon content determination, and reaction kinetic measurements. J. Phys. Chem. 84 3363-3370 (1980).

8. Jung, H. J., Vannice, M. A., Mulay, L. N., Stanfield, R. M. \& Delgass, W. N. The characterization of carbon-supported iron catalysts: chemisorption, magnetization, and Mössbauer spectroscopy. J. Catal. 76, 208-224 (1982).

9. Weller, S., Hofer, L. J. E. \& Anderson, R. B. The role of bulk cobalt carbide in the Fischer-Tropsch Synthesis. J. Am. Chem. Soc. 70, 799-801 (1948).

10. Anderson, R. B., Hall, W. K., Krieg, A. \& Seligman, B. Studies of the Fischer-Tropsch Synthesis. V. Activities and surface areas of reduced and carburized cobalt catalysts. J. Am. Chem. Soc. 71, 183-188 (1949).

11. Gruver, V. et al. Deactivation of a Fischer-Tropsch catalyst through the formation of cobalt carbide under laboratory slurry reactor conditions. Prepr. Pap. -ACS, Div. Pet. Chem. 49, 192-194 (2004).

12. Xiong, J. M. et al. The formation of $\mathrm{Co}_{2} \mathrm{C}$ species in activated carbon supported cobalt-based catalysts and its impact on Fischer-Tropsch reaction. Catal. Lett. 102, 265-269 (2005).

13. Tavasoli, A., Malek Abbaslou, R. M. \& Dalai, A. K. Deactivation behavior of ruthenium promoted $\mathrm{Co} / \gamma-\mathrm{Al}_{2} \mathrm{O}_{3}$ catalysts in Fischer-Tropsch synthesis. Appl. Catal. A 346, 58-64 (2008)

14. Karaca, H. et al. Structure and catalytic performance of Pt-promoted aluminasupported cobalt catalysts under realistic conditions of Fischer-Tropsch synthesis. J. Catal. 277, 14-26 (2011).

15. Mohandas, J. C. et al. Fischer-Tropsch synthesis: characterization and reaction testing of cobalt carbide. ACS Catal. 1, 1581-1588 (2011).

16. Pan, Z. \& Bukur, D. B. Fischer-Tropsch synthesis on $\mathrm{Co} / \mathrm{ZnO}$ catalyst-Effect of pretreatment procedure. Appl. Catal. A 404, 74-80 (2011).

17. Hofer, L. J. E. \& Peebles, W. C. X-Ray diffraction studies of the action of carbon monoxide on cobalt-thoria-kieselguhr catalysts. J. Am. Chem. Soc. 69, 2497-2500 (1947)

18. Weller, S. Kinetics of carbiding and hydrocarbon synthesis with cobalt Fischer-Tropsch catalysts. J. Am. Chem. Soc. 69, 2432-2436 (1947).

19. Claeys, M. et al. In situ magnetometer study on the formation and stability of cobalt carbide in Fischer-Tropsch synthesis. J. Catal. 318, 193-202 (2014).

20. Jalama, K. Fischer-Tropsch synthesis over $\mathrm{Co} / \mathrm{TiO}_{2}$ catalyst: effect of catalyst activation by $\mathrm{CO}$ compared to $\mathrm{H}_{2}$. Catal. Commun. 74, 71-74 (2016).

21. Paterson, J., Peacock, M., Ferguson, E., Purves, R. \& Ojeda, M. In situ diffraction of Fischer-Tropsch catalysts: cobalt reduction and carbide formation. ChemCatChem 9, 3463-3469 (2017).

22. Xiang, Y. \& Kruse, N. Tuning the catalytic CO hydrogenation to straight- and long-chain aldehydes/alcohols and olefins/paraffins. Nat. Commun. 7, 13058 (2016).

23. Zhong, L. et al. Cobalt carbide nanoprisms for direct production of lower olefins from syngas. Nature 538, 84-87 (2016).

24. $\mathrm{Li}, \mathrm{Z}$. et al. Effects of sodium on the catalytic performance of CoMn catalysts for Fischer-Tropsch to olefin reactions. ACS Catal. 7, 3622-3631 (2017).

25. Zhao, Z. et al. Insight into the formation of $\mathrm{Co@} \mathrm{Co}_{2} \mathrm{C}$ catalysts for direct synthesis of higher alcohols and olefins from syngas. ACS Catal. 8, 228-241 (2017).

26. An, Y. et al. Morphology control of $\mathrm{Co}_{2} \mathrm{C}$ nanostructures via the reduction process for direct production of lower olefins from syngas. J. Catal. 366, 289-299 (2018)

27. An, Y. et al. Effect of reaction pressures on structure-performance of $\mathrm{Co}_{2} \mathrm{C}$ based catalyst for syngas conversion. Ind. Eng. Chem. Res. 57, 15647-15653 (2018).

28. Xiang, Y. et al. Long-chain terminal alcohols through catalytic CO hydrogenation. J. Am. Chem. Soc. 135, 7114-7117 (2013).

29. Paterson, J. et al. Manipulation of Fischer-Tropsch synthesis for production of higher alcohols using manganese promoters. ChemCatChem 10, 5154-5163 (2018).

30. Johnson, G. R., Werner, S. \& Bell, A. T. An investigation into the effects of Mn promotion on the activity and selectivity of $\mathrm{Co} / \mathrm{SiO}_{2}$ for Fischer-Tropsch synthesis: evidence for enhanced $\mathrm{CO}$ adsorption and dissociation. ACS Catal. 5, 5888-5903 (2015).

31. Johnson, G. R. et al. Investigations of element spatial correlation in Mnpromoted Co-based Fischer-Tropsch synthesis catalysts. J. Catal. 328, 111-122 (2015).

32. Denzil, J. M., Jan van de, L., Hans, J. W. N. \& Abdool, M. S. in Advances in Fischer-Tropsch Synthesis, Catalysts, and Catalysis Chemical Industries (CRC Press, 2009).

33. Ducreux, O., Lynch, J., Rebours, B., Roy, M. \& Chaumette, P. in Studies in Surface Science and Catalysis. Vol. 119 (eds Parmaliana, A., Sanfilippo, D., Frusteri, F., Vaccari, A., \& Arena, F.) 125-130 (Elsevier, 1998).

34. in Studies in Surface Science and Catalysis Vol. 86 (eds Slin'ko, M. M., \& Jaeger N. I.) 47-120 (Elsevier, 1994). https://www.sciencedirect.com/science/article/ abs/pii/S0167299108615396?via\%3Dihub.

35. Heinze, S., Schmatloch, V. \& Kruse, N. Hysteresis effects and long-period oscillations of the $\mathrm{D}_{2} \mathrm{NO}$ reaction on $\mathrm{Rh}(110)$. Surf. Sci. 341, 124-132 (1995). 
36. Suchorski, Y. et al. Visualizing catalyst heterogeneity by a multifrequential oscillating reaction. Nat. Commun. 9, 600 (2018)

37. Tsotsis, T. T., Rao, V. U. S. \& Polinski, L. M. Reaction rate oscillations during Fischer-Tropsch synthesis on Fe-precipitated $\mathrm{Nu}-1$ zeolite-type catalysts. AIChE J. 28, 847-851 (1982).

\section{Acknowledgements}

This work was supported by National Science Foundation under contract No. CBET1438227. A portion of the research was performed at EMSL, a national scientific user facility sponsored by the Department of Energy's Biological and Environmental Research and located at PNNL. PNNL is a multiprogram national laboratory operated for the U.S. DOE by Battelle.

\section{Author contributions}

Y.X. performed the catalytic measurements, XRD characterization, and contributed to drafting the paper. L.K. performed HAADF-STEM and HRTEM characterization. N.K. initiated the research project and drafted the paper.

\section{Additional information}

Supplementary Information accompanies this paper at https://doi.org/10.1038/s41467019-11836-z.

Competing interests: The authors declare no competing interests.
Reprints and permission information is available online at http://npg.nature.com/ reprintsandpermissions/

Peer review information: Nature Communications thanks the anonymous reviewer(s) for their contribution to the peer review of this work. Peer reviewer reports are available.

Publisher's note: Springer Nature remains neutral with regard to jurisdictional claims in published maps and institutional affiliations.

\begin{abstract}
(c) (i) Open Access This article is licensed under a Creative Commons Attribution 4.0 International License, which permits use, sharing, adaptation, distribution and reproduction in any medium or format, as long as you give appropriate credit to the original author(s) and the source, provide a link to the Creative Commons license, and indicate if changes were made. The images or other third party material in this article are included in the article's Creative Commons license, unless indicated otherwise in a credit line to the material. If material is not included in the article's Creative Commons license and your intended use is not permitted by statutory regulation or exceeds the permitted use, you will need to obtain permission directly from the copyright holder. To view a copy of this license, visit http://creativecommons.org/ licenses/by/4.0/.
\end{abstract}

(c) The Author(s) 2019 